\title{
HVMANITAS
}

\section{Três momentos na existência do Mosteiro de Santa Clara-a-Velha}

\section{Autor(es): $\quad$ Toipa, Helena Costa}

Publicado por: $\begin{aligned} & \text { Faculdade de Letras da Universidade de Coimbra, Instituto de Estudos } \\ & \text { Clássicos }\end{aligned}$

URL

persistente:

DOI: $\quad$ DOI:http://dx.doi.org/10.14195/2183-1718_61_13

Accessed : $\quad$ 26-Apr-2023 10:43:18

A navegação consulta e descarregamento dos títulos inseridos nas Bibliotecas Digitais UC Digitalis, UC Pombalina e UC Impactum, pressupõem a aceitação plena e sem reservas dos Termos e Condições de Uso destas Bibliotecas Digitais, disponíveis em https://digitalis.uc.pt/pt-pt/termos.

Conforme exposto nos referidos Termos e Condições de Uso, o descarregamento de títulos de acesso restrito requer uma licença válida de autorização devendo o utilizador aceder ao(s) documento(s) a partir de um endereço de IP da instituição detentora da supramencionada licença.

Ao utilizador é apenas permitido o descarregamento para uso pessoal, pelo que o emprego do(s) título(s) descarregado(s) para outro fim, designadamente comercial, carece de autorização do respetivo autor ou editor da obra.

$\mathrm{Na}$ medida em que todas as obras da UC Digitalis se encontram protegidas pelo Código do Direito de Autor e Direitos Conexos e demais legislação aplicável, toda a cópia, parcial ou total, deste documento, nos casos em que é legalmente admitida, deverá conter ou fazer-se acompanhar por este aviso. 
humanitas

\section{Vol. LXI}

IMPRENSA DA UNIVERSIDADE DE COIMBRA

COIMBRA UNIVERSITY PRESS 


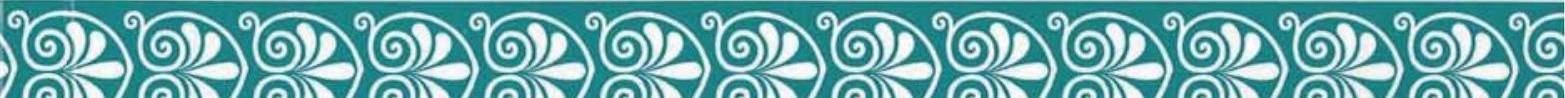

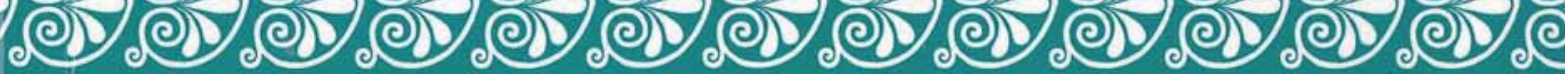

Vol. LXI 


\title{
TRÊS MOMENTOS NA EXISTÊNCIA DO MOSTEIRO DE SANTA CLARA-A-VELHA
}

\author{
Helena Costa Toipa \\ Centro de Estudos Clássicos e Humanísticos \\ helenacosta@crb.ucp.pt
}

\begin{abstract}
Resumo
Submerso até há muito pouco tempo, aquilo que resta do complexo de edifícios do Mosteiro de Santa Clara-a-Velha foi de novo, agora, trazido à luz, afastadas as águas do rio Mondego. Desde a construção do edifício, no século $\mathrm{XIV}$, que o rio fez sentir a sua força e foi invadindo o espaço, ao longo de poucos séculos, até o tornar inabitável, forçando o seu abandono, no século XVII. Desta progressiva conquista, pelas águas, do Mosteiro da Rainha Santa Isabel, destacámos três testemunhos: um contemporâneo da construção; outro do século XVI, de um padre jesuíta do Colégio das Artes, Pedro Perpinhão; o último, do historiador dos franciscanos, Fr. Manoel da Esperança, do século XVII.

Palavras-chave: Mosteiro de Santa Clara-a-Velha, Rainha Santa Isabel, Lenda da Rainha Santa, Pedro Perpinhão, Fr. Manoel da Esperança.

\footnotetext{
Abstract

Being underwater until a few years ago, the remains of Santa Clara's old monastery are now brought to light again, as soon as the river Mondego's waters have been removed. Since its construction, on the $14^{\text {th }}$ century, the monastery has been invaded by the river and after three centuries, it became uninhabitable; it was therefore abandoned during the $17^{\text {th }}$ century. From the water's advancing conquest, we selected three testimonies: one contemporary of the construction date; another from the $16^{\text {th }}$ century, written by a Jesuit priest, Pedro Perpinhão; and finally, another written by a friar of the Franciscan order, Fr. Manoel da Esperança, from the $17^{\text {th }}$ century.
} 
Keywords: Santa Clara's Old Monastery, Queen Saint Elizabeth, Lenda da Rainha Santa, Pedro Perpinhão, Fr. Manoel da Esperança.

Foi recentemente trazido de novo à luz, liberto das águas e das areias do Mondego ${ }^{1}$, o que resta do complexo de edifícios que constituía o Mosteiro de Santa Clara-a-Velha e anexos. E o que resta é simplesmente a Igreja e o Claustro, pois os outros edifícios, também mandados construir pela Rainha Santa Isabel, já tinham desaparecido antes da acentuada submersão do mosteiro, segundo testemunho de autores contemporâneos desses desaparecimentos.

Quando falamos do Mosteiro de Santa Clara-a-Velha, a associação à figura da Rainha Santa Isabel é imediata, pelo papel fundamental que ela teve na sua construção e florescimento. Por isso, as biografias desta rainha apresentam, todas elas, como não podia deixar de ser, informação sobre a sua dedicação e o seu empenho na construção e manutenção desta complexa edificação, que incluía igreja, claustros, um paço régio onde costumava alojar-se quando residia em Coimbra, para estar próxima das clarissas, e alojamentos para homens e mulheres carenciados, de vida honesta, com a respectiva igreja e cemitério.

O primeiro documento biográfico da rainha é um texto de autor desconhecido, que andou manuscrito por muito tempo na biblioteca do Mosteiro, onde foi consultado por todos os biógrafos seguintes e cronistas que se debruçaram sobre os reinados de D. Dinis e D. Afonso IV, e que foi escrito muito pouco tempo depois da sua morte, que ocorreu em 1336; foi editado pela primeira vez por Fr. Francisco Brandão, na Monarchia Lusitana, parte VI, com o título "Relaçam da vida da gloriosa Santa Isabel, Rainha de Portugal", e depois reeditado, com nova leitura e mais completa, por José Joaquim Nunes, no Boletim da Classe de Letras da Academia das Ciências de Lisboa, em 1921, com o título "Livro que fala da boa vida que fez a Raynha de Portugal, Dona Isabel, e dos seus bõos feitos e milagres em sa vida e depoys da morte". É este último texto que seguiremos e citaremos, referindo-o pela designação tradicional de Lenda da Rainha Santa.

Neste texto se refere a origem do monumento e o papel da rainha para a resolução do impasse a que se tinha chegado depois de longa contenda

${ }^{1}$ A recuperação do complexo foi da responsabilidade do Instituto Português do Património Arquitectónico. 
judicial e o empenho e entusiasmo que colocou na edificação do Mosteiro onde, depois de viúva, viria a passar grande parte do seu tempo e em cuja igreja escolheu ser sepultada.

O mosteiro de Santa Clara teve um início atribulado; fora fundado por D. Mór Dias, uma abastada dama da nobreza que, decidindo afastar-se do mundo, recolhendo-se num mosteiro, em 1250, sem, no entanto, professar, para poder continuar a possuir e a administrar os seus bens, começara por escolher para a sua reclusão, o mosteiro feminino da Ordem de Santa Cruz, em Coimbra, onde viveu algum tempo, aparentemente em situação de poder dispor dos seus bens. Poucos anos depois, por volta de 1278, mandava ela construir, junto do Mondego, umas casas e, em 1283, obtinha autorização para fundar um mosteiro onde pudesse recolher-se, da ordem de Santa Clara, dedicando-o a Santa Isabel de Hungria.

Os Cónegos Regrantes de Santa Cruz, no entanto, não aceitaram pacificamente esta transferência de Mór Dias e da sua fortuna para outra instituição e iniciaram contra ela uma demanda, argumentando que tinha professado na sua ordem e que, como tal, quer a pessoa quer os seus bens lhes pertenciam. O conflito prolongou-se por vários anos, contando mesmo com a intervenção da Santa Sé, quer em vida da fundadora, quer depois da sua morte, que ocorreu em 1303. Finalmente, por decisão do tribunal, favorável aos frades de Santa Cruz, as clarissas foram expulsas e o mosteiro ficou desabitado. (Lenda, 1921: 1336-1337)

Foi a intervenção da Rainha D. Isabel de Aragão que veio dar novo alento à iniciativa de Mór Dias: contribuiu para a composição das partes em litígio; solicitou autorização para fundar um mosteiro de invocação a Santa Clara, naquele mesmo lugar onde o quisera D. Mór Dias, mas agindo como se começasse de novo, comprando os terrenos em redor, e planeando uma grande construção, cujas obras decorriam já em 1316. O mosteiro conheceu, após a intervenção da rainha, o seu grande desenvolvimento (Lenda 1921: 1337-1338).

Para seguir de perto e orientar a construção, quando estivesse em Coimbra, a rainha mandou construir, nas proximidades, uma casa para si e para os seus, que posteriormente acompanhou de outros edifícios, destinados a um hospício que albergaria separadamente 15 homens e 15 mulheres pobres, com a respectiva capela e cemitério consagrados; estes edifícios ficariam, à sua morte, propriedade do mosteiro. (Lenda 1921: 1344-1346).

A Rainha decidiu também escolher para seu eterno descanso a igreja do Mosteiro e tratou de mandar fazer o seu túmulo. Foi colocado no meio 
da Igreja, mas desde logo, as águas do Mondego se mostraram ameaçadoras, dando sinal já do destino que havia de sofrer esta vasta edificação, que foi conquistada, ao longo dos séculos, pelas águas, das quais só recentemente se voltou a libertar.

"E, acabada a eigreja do moesteiro e abobeda, fez poer o moimento que ela já tiinha feito pera sa sepultura em meo da eigreja. E per razom do moimento, que era mui grande e per razom das gradizelas, postas por derredor, que tiinham gram parte da eigreja, ficava embargada muito. E em aquel tempo que o moimento na eigreja seia sobreveo uu deluvio d'augua em Coimbra, dezoito dias de Fevereiro, era 1369 anos, que entrou a augua do rio Mondego, que vem por redor da cidade de Coimbra, per aquela eigreja, e em tanto que nom era naquele tempo em memoria dos omees que aquela augua a tal logar veesse chegar, nem que aquel rio tam creçudo fosse, e foi tanta a augua do rio em na eigreja, que foi aquel moimento cuberto d'augua. E a rainha, veendo em como o rio aaquel logo chegara e veendo em como per aquel asseentamento a eigreja era embargada, ordiou logo como se fezesse em aquela eigreja, que era alta quanto compria, sobre arcos ua capela alçada em meo da eigreja como coro, pera as donas estarem, e fez fazer departimento grande antre o coro e a capela, e fez em cima poer aquel seu moimento e sepultura, que tiinha em fundo, e fez ali poer o moimento da ifante Dona Isabel, sa neta, que ela criara e passara em sa casa e fez fazer altar e imagees e seedas, para seerem os creligos e os outros que veessem i ouvir as oras ou dizerlas, e assi, per razom da augua que entrou em na eigreja, á ora em na eigreja duas eigrejas e dous coros; e teverom que a Deus aprouguera de se assi fazer, quando a el prouguera de entrar aquela augoa em aquela eigreja e u nom soía entrar." (Lenda 1921: 1347-1348). ${ }^{2}$

${ }^{2} \mathrm{O}$ acrescento da capela funerária forneceu a cota a partir da qual se fez um novo pavimento de toda a área da igreja, nos inícios do século XVII:

"O original acrescento desta capela funerária, a meia altura do templo, na zona de bipartição do espaço eclesiástico, não só marcou consideravelmente o espaço da igreja, como também forneceu a cota para ser lançado, nos inícios do século XVII, um novo pavimento em toda a área da igreja.

$\mathrm{O}$ alteamento dos pavimentos, como forma de resistir às inundações, foi outras vezes utilizado, como a escavação mostrou, embora nunca de forma tão radical como a que teve lugar na edificação da capela funerária e, posteriormente, no referido piso, datado do século XVII." (Macedo 2003: 18). 
Deste túmulo da rainha, faz o padre jesuíta Pedro Perpinhão, séculos depois, em 1559, uma descrição um pouco mais detalhada, apelando mesmo à visualização por parte dos auditores, numa oração em louvor da Rainha, integrada nas comemorações anuais instituídas por D. João III para o dia 4 de Julho:

Constitutum est in illo superiore sacello, ubi nunc cernitur. Nitebatur ut etiam nunc uidetis, octo leonibus, multis undique sigillis ornabatur, una imago Reginae pergrandis, uirginum Sanctae Clarae habitu, manibus iunctis, et pedibus instar mortuae iacebat in summo. Nunc uero liberalitate mulierum sacrarum et pietate magnificentius exornatum est. Nitent omnia pulcherrimis coloribus, et auro et testudine lignea egregie depicta teguntur, quae ex omnibus angulis quattuor columellis affabre factis e ligno sustinetur $(\ldots)^{3}$

Foi colocado na capelinha superior, onde agora se vê. Apoiava-se, como também agora vedes, sobre oito leões e era ornado, de todos os lados, por muitas figurinhas. Uma imagem muito grande da Rainha, vestida com o hábito das freiras de Santa Clara, com as mãos juntas, bem como os pés, semelhante à falecida, jazia por cima. A verdade é que, graças à liberalidade e piedade destas santas mulheres, ele está magnificamente ornado. Tudo brilha em belíssimas cores e está coberto de ouro e de uma abóbada de madeira excelsamente pintada, que é suportada, de todos os ângulos, por quatro colunelos preciosamente feitos de madeira. ${ }^{4}$

Deste alteamentos, Perpinhão refere apenas o da capela funerária, não fugindo ao relato da Lenda; Fr. Manoel da Esperança (1666: 34-35) já menciona os outros no seu texto (vd. infra).

${ }^{3}$ Petri Ioannis Perpiniani, "Laudationis in B. Elizabetham Lusitaniae Reginam Liber III", in Orationes duodeuiginti, 1589, Pompelonae, p. 66v.

${ }^{4}$ Das sepulturas da Igreja do Mosteiro, Perpinhão fala apenas da de Santa Isabel; mas outras existiam, muito estragadas pela água, como refere o frade franciscano Fr. Manoel da Esperança (1666: cap. XXII):

"Outras duas sepulturas aparecem na Igreja, as quaes d'antes pizavão leões de pedra, \& agora se sentem mui ofendidas das injurias do tempo. Ambas tem insignias Reaes, faltão porém epitáfios, que nos digão cujas são.

2 Numa dellas, entalhada pelas faces com muitas Imagens santas, está deitado o vulto de hua minina com os seus cabelos soltos, \& as roupas seculares. Tem as mãos levantadas, \& encostadas no peito, os pés ambos firmados em hum leão; \& na cabeça, hua coroa Real. Acompanhão os seus lados dous Anjos de cada parte, \& dous escudos Reaes: huns delles com 
Pedro Perpinhão, valenciano, viera para Portugal em 1551, com 21 anos de idade, e, nos Colégios da Companhia de Jesus, fora, primeiro, estudante e, depois, professor de Latim, exercendo a sua actividade em Évora (1554) e principalmente em Coimbra (1555-1560), no Colégio das Artes. Este fundado por D. João III, iniciara a sua actividade em 1548, sob a direcção de André de Gouveia, e, em 1555 fora entregue pelo monarca à Companhia, instalada em Portugal havia pouco mais de uma dúzia de anos.

Quinas de Portugal: os outros com Barras de Aragão. E tudo isto nos mostra, qual póde ser o depósito, que aqui se encerrou: quero dizer, a ossada da Infanta D. Isabel, filha d'Elrei D. Afonso IV, \& da Rainha D. Brites, \& neta da dita Santa Rainha.(...)

$3 \mathrm{Na}$ outra, que também he hua arca de pedra, jaz deitada a figura de hua molher, Religiosa no habito, cingida com um cordão, véo na cabeça, \& toalha sobqueixada em sinal da sua honestidade. Tinha as mãos levantadas ao Ceo: agora as tem quebradas, como os Anjos, que lhe assistem nos lados. Os escudos gravados na mesma pedra, que cercão este sepulchro, nos declarão que he pessoa Real, pertencente pelas Barras à Casa de Aragão, \& pelas Quinas á nossa de Portugal. O banco, que aparece na orla, mostra também ser Infanta; \& pela Cruz de Aviz, na qual assentão as Quinas na forma, que as dispoz Elrei D. João I, se ve manifestamente como teve alguma rezão com elle."

Prossegue o ilustre historiador a descrição de outras sepulturas existentes na Igreja do Mosteiro, à data em que escreve. Primeiro a de D. Brites, "meia irmam da nossa Rainha Santa" que "descançava da grade do coro para dentro"; depois a de seu filho, D. Guilhem de Cardona, que descansava na "na capela colateral, a maior da banda esquerda, onde eu fiz descobrir o seu túmulo a pezar da grande destruição, que o Mondego tem feito nesta Igreja." Esse túmulo "era lavrado com singular artifício, de modo que vivamente estava representado na parte superior a pessoa deste mesmo D. Guilhem, assi na gravidade do rosto, como também na galante bizarria, com que puxava da espada, que tinha embainhada. Aparecião à roda, entre Imagens, \& insignias de Santos, muitas figuras de molheres, \& de homens: aquellas, que arranhavão o rosto: estes, arrepelando as barbas". Para além destas ilustres figuras ligadas à Rainha Santa, outras estavam ali sepultadas, segundo testemunho presencial de Fr. Manuel da Esperança: Gonçalo Pires Ribeiro e sua mulher D. Constança Lourenço, D. Isabel Coutinho, D. Joana Gonçalves Redondo e D. Mécia Pestana, entre outras personagens ligadas à vida do Mosteiro, como as abadessas. 
Perpinhão era, além de professor, o orador escolhido pelos seus superiores para qualquer solenidade; foi ele quem, em nome dos jesuítas, pronunciou a oração de sapiência nesse ano de 1555, na abertura do ano lectivo (De Societatis Iesu Gymnasiis, et de eius docendi ratione); foi ele que, nesse mesmo ano, disse a oração fúnebre quando da morte do Infante D. Luís, irmão do rei (Laudatio funebris Ludouici Principis); foi ele, ainda, que pronunciou, em três anos consecutivos $(1557,1558,1559)$ as orações em louvor da Rainha Santa, instituídas como homenagem pelo rei D. João III, para o dia 4 de Julho (Laudationis in Beatam Elisabetham Lusitaniae Reginam libri tres). A par destas orações laudatórias, Perpinhão dedicou-se também à redacção de uma monografia sobre a Rainha, que dividiu em três livros (De uita et moribus Diuae Elisabethae Lusitaniae Reginae libri tres). A fonte histórica que serve de fio condutor é a Lenda acima citada. Mas Perpinhão recorreu a várias outras fontes de informação, escritas ou orais, privilegiando em determinadas circunstâncias, a observação; com efeito, no momento em que compõe a biografia, o Mosteiro está ainda habitado e funcional, apesar da derrocada recente de um dos edifícios anexos.

Com efeito, o paço régio construído pela rainha para sua morada, enquanto residisse em Coimbra, ruiu em 1559, ano em que Perpinhão ainda estava em Portugal e compondo a monografia da Rainha. Relata até um episódio curioso ocorrido durante a derrocada: um rapaz que ali se abrigara saiu incólume dos escombros, protegido por uma espécie de grade que se formou com as traves do edifício:

Ea domus usque ad hanc memoriam annos circiter tres et triginta supra ducentos integrastetit; (...)Anno uero ab ortu Christi seruatoris quingentesimo nono supra millesimum, cum hoc totum factum aestate superiore fuisset in lucem prolatum a nobis altera oratione de rebus a Regina gestis, priusquam tertia, quae fuit extrema, diceretur, ineunte uere, nocte S. Matthiae ferias antecedente, cum et uetustate nemine reficiente consumpta, et maximis atque assiduis imbribus hyemis proxime dissoluta esset, inquilinis innoxia, corruit magna ex parte (...). Nam et pridie eius diei rimis actis, ac uelut ante denuntiata ruína omnes, ut alio migrarent, admonuit, antequam opprimerentur, et puerum, qui solus cum iumento remanserat in imis aedibus, trabibus a solo ad alterum parietem stantem cratis in modum quasi de industria erectis, et pondus ruentis tecti sustinentibus ita molliter excepit, ut multorum diligentia breui purgato loco, puluere quidem obsitus, sed prorsus integer extraheretur, quem omnes suspicarentur esse penitus obtritum. 
Esta casa permaneceu inteira até à nossa época, durante cerca de duzentos e trinta e três anos (...). No ano de Cristo Salvador de mil quinhentos e cinquenta e nove, tendo toda esta situação sido trazida à luz, por nós, no verão passado, numa outra oração sobre os feitos da rainha, antes de se ter dito a terceira, que foi a última, no começo da Primavera, na noite que antecedeu o feriado de S. Matias, por estar não só consumida pela decrepitude por ninguém restaurada, mas também abalada com as abundantes e frequentes chuvas do último inverno, sem inquilinos, ruiu, em grande parte (...) Com efeito, na véspera desse dia, abrindo fendas, tal como antes de uma ruína anunciada, deu sinal a todos que partissem para outro lugar, antes que fossem esmagados; no entanto, a um rapaz que permanecera sozinho com um burro, nos aposentos interiores, como as traves se erguessem como que deliberadamente do solo para a outra parede que estava de pé, à maneira de uma grade, e sustentassem o peso do tecto a ruir, de tal forma suave o conservou que, ao limpar-se todo o lugar, graças à diligência de muitos, foi tirado coberto de pó, é verdade, mas completamente intacto aquele que todos suspeitavam estar completamente esmagado.

(De uita et moribus B. Elisabethae Lusitaniae Reginae Libri III, ... 305-391)

Sobre esta derrocada e o episódio descrito por Perpinhão, fala também Fr. Manoel da Esperança, enfatizando a acção nefasta do rio. Escreve aproximadamente um século depois de Perpinhão sobre o mosteiro de Santa Clara-a-Velha, já em avançado estado de submersão pelas águas do rio e prestes a ser abandonado pelas freiras, uma vez que se iniciara já a construção do novo mosteiro, por iniciativa de D. João IV:

"Mas o Mondego, destruidor insolente de edifícios nobres, assi como não receou ofender o sagrado do mosteiro, não teve também respeito a paços nem hospital. No anno de 1559 se humilharão os paços com hua ruina grande, da qual a S. Rainha, que os tinha levantado, deu avizo por sinais mui evidentes a quantos estavão nelles pera que se resguardassem. E ficando hu moço mal advertido, as mesmas traves, que desarmarão de sima, se fizerão em hum corpo, sustentando sobre si o pezo, \& o entulho, que o podia matar." (Segunda Parte, Livro VI, Cap. XX)

Sobre o estado dos albergues construídos pela rainha, falam também Perpinhão e Fr. Manoel da Esperança. O primeiro refere que: 
Huius tantae liberalitatis etiam nunc tenuia et obscura uestigia comparent; constant enim adhuc illa tecta circum regiae ruinas frequentissime a pauperibus habitata, cum uetustissimo sacello, in quo, dominicis diebus unus aliquis sacerdos ex finitima S. Francisci aede sacris operatur et duodecim mulieres egentes aluntur in illo Parthenone S. Clarae, certa pecunia, quam Elisabetha quondam dicitur atribuisse.

Desta tão grande liberalidade e humanidade, ainda hoje se encontram alguns ténues e obscuros vestígios. Com efeito, conservam-se ainda esses edifícios, em volta das ruínas do paço régio, muito frequentemente habitado por pobres, com a sua antiquíssima capela, na qual, aos domingos, um dos sacerdotes da vizinha casa de S. Francisco celebra os rituais. E 12 mulheres pobres são providas, neste convento de Santa Clara, de algum dinheiro, como se diz ter outrora atribuído Isabel.

(De uita et moribus B. Elisabethae Lusitaniae Reginae Libri III, ... 305-391)

O segundo (1666. 44) constata já o desaparecimento do edifício principal, por acção também das cheias do rio, que levaram também ao alteamento da igreja:

“O Hospital teve a mesma desgraça de cair pera nunqua se erguer. Não ficou delle em pé, senão a sua Igreja, mas tão cativa das cheas, que pera se por em salvo, ao menos o Altar, subio por doze degraos. Nesse tempo, que foi na nossa idade, se levantou o alpendre numas colunas antigas, que já avião servido noutra obra do mosteiro, da qual falão estas letras, que ainda se vem nellas. Senhora D. Margarida de Menezes fez esta obra 1520. Assi se vão desfazendo os maiores edifícios que parecião eternos, representandonos todos, pera nosso desengano, a semelhança da morte, que em nos não tem falência."

Do mosteiro propriamente dito, isto é, da igreja e dos claustros fala, com conhecimento de causa, Perpinhão, que o visitou certamente, quer no âmbito da sua tarefa de discursar nos dias consagrados às festividades da Rainha, quer no exercício da redacção da monografia; para ambas as circunstâncias, consultou, como ele próprio refere na monografia, o manuscrito da Lenda, seguindo fielmente o seu relato, mas acrescentando dados da sua observação.

Ao fazer a descrição destes edifícios começa por referir o pátio, passando, depois, ao templo: 
Primum, quadrata est area latitudine mediocri, tribus ex lateribus humilioribus aedificiis iam tum ab initio cincta, ubi partim sacri collegii necessariae ministrae, partim inopes mulieres, quibus quotidiana cibaria praebentur, habitant; quartum latus ad meridiem uergens templo ipso clauditur, porticu non magna a ualuis ad Parthenonis ianuam pertinente; id saxo quadrato antiqua illa opera, et artificio perfectum, tecto cocamerato, duobus ingentium pilarum ordinibus triplicem testudinem sustinentibus, mulotis tabulis pictis et beatorum signis adornatur. E regione tholi, quo tegitur ara maxima, duplex odeum est, ut supra significauimus, unum plano pede, alterum supra concamerationem in altitudinem elatam, ante sacellum structum superiore loco, et sepulcrum Elisabethae; ipsum autem sacellum duplicem habet aditum, alterum ex templo gradibus lapideis bene factis, ostio maiore, alterum ex porticu externa, arcto humilique ostiolo, iisdem quibus adi anuam ascenditur, scalis.

(De uita et moribus B. Elisabethae Lusitaniae Reginae Libri III, ... 305-391) Primeiro, existe uma área quadrangular, de latitude mediana, cingida já, então, desde o início, dos três lados, pelos edifícios mais humildes, onde, em parte, habitam as servidoras necessárias ao sagrado colégio, em parte, as mulheres pobres, a quem se fornece alimentação diária. O quarto lado, voltado para sul, é fechado pelo próprio templo, com um pórtico não muito grande, que se estende das portas de batente até à porta do mosteiro.

O templo, feito com pedra quadrada, naquela antiga arte e engenho, com o tecto em abóbada, com duas fileiras de enormes pilares sustentando a cobertura abobadada tríplice, está ornado com muitos quadros e estátuas de santos. Diante de cúpula que cobre o altar-mor está o duplo coro, como acima referimos, um de pé plano, outro sobre uma abóbada elevada em altura, diante da capelinha erigida em lugar alto e do sepulcro de Isabel. E esta mesma capelinha tem uma dupla entrada, uma partindo do templo, com degraus de pedra bem feitos, pela porta maior, outra partindo do pórtico exterior, por uma humilde entradita a norte, pelas mesmas escadas através das quais se ascende à porta.

Refere depois, Perpinhão, a existência de dois claustros:

Intus duo peristylia magnitudine pari, dispari nobilitate. Alterum iunctum ipsi templo magnificentius exaedificatum est; quattuor enim porticibus, opere testudineato tectis continetur, ea pilarum fornicatos parietes sustinentum mole, ea multitudine columnaram, octonis columnis fulcientibus singulas 
pilas, ut cum omnibus opulentissimorum regum operibus, amplitudine, artificio, firmitate certet. In medio compluuio stagnum est ingens, cuius in quattuor angulis totidem impositi fontes aquam fundunt iucundissimo sono. Iuxta, puteus incremento suo, fluminis inundationes multo ante praenuntiat, magnum incommodum allaturas, nisi illo, uelut e specula signo dato, cauerentur. Quod spatii reliquum est, exquisitissimis herbis, fruticibus, arboribus uiret. Hic, dictu mirum, quinque sunt cubiculorum ordines, quorum quilibet non exíguo coetui satis esse posse uideatur, duo praeterea minores. Hic exaedra longitudine sesquitertia latitudinis fenestrarum, et ostiorum tum frequentia, tum apta descriptione uehementer illustris, cuius interiores parietes emblemate uermiculato uestiuntur, a dignitate, ut ad omnes motus animorum conficiendos facta esse uideatur. Hic denique coenatio tam longe lateque patens, ut ducentae uirgines in ea quam comodissime possint discumbere. Itaque tum propter hanc tam uastam matgnitudinem, tum quia crescente fluuio humore noxio redundat, ea non utuntur; ante eam coenationem, fons est, ad abluendas manus, e saxo, quem impendens testudo, superne operit columnis quadragenis innixa. Proxime stabat platanus, raríssima in his oris arbor $(\ldots)$

(De uita et moribus B. Elisabethae Lusitaniae Reginae Libri III, ... 305-391) Dentro estavam dois claustros, de tamanho semelhante, mas de diferente nobreza. Um, unido ao próprio templo, foi edificado de forma mais magnificente. Com efeito, está limitado por quatro galerias, com tectos de formato abobadado, com uma multidão de pilares sustentando paredes arqueadas $^{5}$, com uma tal quantidade de colunas, em grupos de oito sustentando cada um seu pilar, que rivaliza, em amplitude, em arte e em firmeza, com todas as obras dos reis mais ricos.

No complúvio que está a meio, existe um tanque grande e, dele, nos quatro cantos, outras tantas fontes aí colocadas derramam água com agradabilíssimo som. Ao lado, um poço, quando enche, previne muitos antes que as inundações do rio vão trazer grande incómodo, se não se fugir dele, como se de um sinal dado de um lugar de observação. O que resta do espaço verdeja com ervas requintadíssimas, arbustos e árvores.

Aqui, é admirável de ser dito, existem cinco fileiras de quartos, das quais qualquer uma parecerá poder ser suficiente para uma comunidade não pequena, para além de duas menores. Aqui, uma sala de reuniões, com

${ }^{5}$ Com esta expressão, Perpinhão refere-se provavelmente aos arcos que ornamentavam as paredes das galerias. 
o comprimento de uma vez e um terço da largura, ilustríssima, seja pela abundância de janelas e portas, seja pelo traçado apropriado, cujas paredes interiores são ornadas de mosaico lavrado ${ }^{6}$, com tal dignidade que parece ter sido feita para acalmar todas as revoluções da alma. Aqui, finalmente, um refeitório tão amplo em comprimento e largura que podem sentar-se nele, da forma mais cómoda, duzentas freiras. E, assim, quer por causa desta tão vasta magnitude, quer porque, quando o rio crescia, se enchia com uma humidade doentia, ele não era utilizado. Diante deste refeitório, existia uma fonte para lavar as mãos, feita de pedra, coberta por um tecto abobadado, suspenso e apoiado em 40 colunas. $^{7}$

Nas proximidades estava um plátano, árvore raríssima nestas paragens (...)

\section{Quanto ao outro claustro:}

Alterum peristylium frequentibus arboribus, porticibus, columnis ornatum, sed diuturnitate ipsa iam affectum, coenationem habet lapideis mensis, ubi nunc cibus capitur, et officinas, atque cellas multitudini tantae necessarias; hortus uero bene magnus, et plurimis consitus arboribus, partim ramorum amoenitate gratis, partim pomorum ubertate fructuosis, circumuallatus altíssimo pariete, Nec inhonestam, neque iniucundam animi remissionem praebet assíduo labore fessis. Omnia rursus, qua fluuium spectant, mediocri uelut obiecto muro muniuntur extrinsecus, ad hibernos impetus fluminis arcendos.

O outro claustro está ornado com árvores abundantes, com galerias e com colunas, mas afectado já da própria longevidade; tem um refeitório com mesas de pedra, onde agora se tomam as refeições, e oficinas e quartos necessários para tão grande multidão; o jardim, verdadeiramente grande, plantado com muitas árvores, não só agradáveis pela amenidade dos ramos, mas também úteis pela abundância de frutos, rodeado de um altíssimo muro, oferece, aos que estão cansados de trabalho constante, um descanso de espírito nem desonesto, nem desagradável. Por outro lado, tudo que está voltado para o rio está fortificado, de fora, por um muro mediano, como uma barreira para fazer frente aos ímpetos do rio, no inverno.

${ }^{6}$ As escavações arqueológicas permitiram recolher in situ, no complexo, incluindo a igreja e o claustro, cerca de oito milhares de azulejos, sobretudo hispano-árabes, enquadráveis em cerca de uma centena e meia de padrões (Macedo 2003:22).

${ }^{7}$ Perpinhão refere-se ao lavabo. Leia-se Macedo 2003: 21. 
Revela também informação fidedigna, porque recolhida in loco, o frade franciscano Fr. Manuel da Esperança. Falando da Igreja do Mosteiro, depois de referir as características da sua construção (abobadada, com três naves, toda em cantaria, com uma capela central e duas colaterais, com o sepulcro da rainha sobre o coro, como refere a Lenda), acrescenta as modificações levadas a efeito no seu tempo:

"Sobre esta assentou o seu sepulchro a gloriosa Rainha, \& hum altar, em que se dizia Missa: na de dentro podião estar as freiras, que visitavão as suas santas Reliquias; \& ambas se estenderão agora nos nossos tempos, levantando sobre as mesmas abobadas outra Igreja, \& outro coro de novo, que se pudessem salvar das inundações do rio. $\mathrm{O}$ antigo tinha muita majestade, porque sendo terraplenado, \& baixo, não somente ocupava grande sítio, ornado com muita arte, mas também ficava superior ao lastro da Igreja, nove degraos de altura, pellos quaes da parte da grade se subia para elle. E neste espaço baixo avia alguns altares, \& sepulturas ilustres, que lhe davão muita graça."

Com mais detalhe do que Perpinhão, Fr. Manoel da Esperança, sobre o claustro, que diz ser "largo, \& suntuoso na fabrica", refere que:

"Todos os lados de fora ião tecidos em arcos: huns grandes, outros pequenos: huns abertos, outros fechados, com redes da mesma pedra, por galante artificio. (...) Na quadra, que corria pela banda do Mondego, ficava o refeitório, \& logo defronte delle se erguia hua casa fermosissima sobre colunas, \& arcos, onde lavavão as mãos num chafariz curioso as que vinhão receber o tributo ordinário da refeição corporal. No meio do mesmo claustro descuberto ao ceo, ocupava grande campo hum tanque mui aprazível, em o qual desagoavão muitas fontes por diferentes figuras, \& a maior, que eu ainda achei, pela boca de uma serpe, enroscada no braço de hua Ninfa. Vinha de fora a agoa, por hum cano, que se chamou dos amores por razão de hua fonte deste nome, onde tem seu principio." (1666: 35).

Sobre as restantes edificações do mosteiro, lamenta o estado de degradação e inacessibilidade a que tinham chegado, referindo também o levantamento de algumas dependências, para evitar a "cisterna viva" em que se transformara o claustro: 
"5 Conforme a estas plantas eraõ os mais edifícios, \& oficinas da casa: todos grandes, suntuosos, \& perfeitos (...) Porèm a nossa desgraça, que alterou a soberba do sobredito Mondego pera sepultar entre as suas arèas os mesmos campos, que se deixavão rasgar pêra ela ter passagem, o fez tãbem atrevido na fea destruição deste insigne mosteiro santificado por muitas servas de Deos, \& mais em particular por esta S. Rainha. Corta por certo a alma ver taõ grande perdição; porque de alguas oficinas não ha mais que o seu rastro, $\&$ quasi todo desfeito pelas enchentes do rio. Outras jazem entulhadas com o lodo, sem se poder usar dellas. O claustro he hua cisterna viva, que nem no verão se seca. De maneira, que os baixos desta grandiosa machina, ou já perderão o ser, ou estão desfigurados, ou convertidos em charcos. Pelo que foi necessário levantar em muitas partes sobre as casas antigas outro mosteiro mais alto, \& passar as capelas, \& ermidas pêra a cabeça do claustro, onde estão coroando, a pezar deste tristíssimo pego, o monte da Santidade. A respeito destes danos, os quaes hoje são maiores, quis Elrei D. Manoel tirar d'aqui o mosteiro em virtude de hua bula do Papa Julio II; \& se as Freiras então, por não saírem deste lugar tão sagrado, resistirão à mudança: agora, que se vem mais apertadas, aceitão com muito gosto, \& grandes ventajens suas (...) (1666: 36)

"6 Faz ainda ao mosteiro entrada o seu pateo antigo, mas muito desfigurado da primeira fermosura, aberto por duas portas, \& ambas mysteriosas. Hua dellas, que olha pera o monte, se chama Porta da Rosa, por memoria de que na mesma paragem o dinheiro, que a Santa Rainha levava pera os pobres, foi convertido em rosas. A outra, que fica pera o Norte, he a porta da cadea, ou do couto, como agora lhe chamão, por estar pregada nella hua cadea de ferro, da qual pêra dentro se prohibe ás Justiças prender os homiziados."

Os relatos apresentados, preciosos testemunhos que permitiram imaginar, enquanto o mosteiro e restantes edifícios estiveram submersos, as características impressas na sua construção e desenvolvimento, fruto da munificência e liberalidade de Rainha Santa Isabel e das clarissas que os ocuparam, permitem também conhecer a sua progressiva e inexorável decadência, fruto do avanço imparável das águas do rio Mondego, que não lhes outorgaram muito mais que três séculos de existência. 


\section{Bibliografia}

Fr. Manoel da Esperança, (1666), Historia Serafica da Ordem dos Frades Menores de S. Francisco na Provincia de Portugal. Segunda Parte. Lisboa: Oficina de Antonio Craesbeeck de Mello.

Macedo, Francisco Pato de (2003), "O mosteiro velho de Santa Clara", in Monumentos. Lisboa: Direcção-Geral dos Edifícios e Monumentos Nacionais, 16-23.

Nunes, J. J. (1921), "Vida e milagres de Dona Isabel, Rainha de Portugal. Texto do século XIV restituído à sua presumível forma primitiva” in Boletim da Classe de Letras. Vol. XIII. Coimbra, 1293-1384.

Perpiniani, P. J. (1749), "De Vita et Moribus B. Elisabethae Lusitaniae Reginae libri III", in Opera, Tomo II, Romae, 305-391.

Perpiniani, P. J, (1589), "Laudationis in B. Elisabetham Lusitaniae Reginam liber III", in Orationes duodeuiginti. Pompelonae, 51-69.

ToIPA, Helena Costa, (2000), A obra de Pedro João Perpinhão em Portugal, Ad Maiorem Dei Gloriam. (Tese de Doutoramento policopiada) Viseu: UCP.

ToIPA, Helena Costa, (1998) "Uma descrição quinhentista do Mosteiro de Santa Clara-a-Velha" Máthesis. Viseu:UCP.

Vasconcelos, António, (1891-1894). Evolução do culto de Dona Isabel de Aragão, esposa do rei lavrador, D. Dinis de Portugal (a Rainha Santa). Reprodução fac-similada. Prefácio e Introdução de Manuel Augusto Rodrigues (1983). Coimbra: Arquivo da Universidade de Coimbra. 